\title{
Physiological Effects of High-Flow Nasal Cannula Therapy and Its Use in Acute Cardiogenic Pulmonary Edema
}

Prakash Adhikari ${ }^{1,2}$, Sanket Bhattarai ${ }^{1}$, Ashish Gupta ${ }^{3}$, Eiman Ali ${ }^{4}$, Moeez Ali ${ }^{1}$, Mohamed Riad ${ }^{1}$, Jihan A. Mostafa ${ }^{5}$

1. Internal Medicine, California Institute of Behavioral Neurosciences \& Psychology, Fairfield, USA 2. Internal Medicine, Piedmont Athens Regional Medical Center, Athens, USA 3. Research, California Institute of Behavioral Neurosciences \& Psychology, Fairfield, USA 4. Pediatrics, California Institute of Behavioral Neurosciences \& Psychology, Fairfield, USA 5. Psychiatry, California Institute of Behavioral Neurosciences \& Psychology, Fairfield, USA

Corresponding author: Prakash Adhikari, pksadhikari88@gmail.com

\begin{abstract}
High-flow nasal cannula (HFNC) is an open oxygen delivery system, which provides heated and humidified oxygen at a high flow (up to $60 \mathrm{~L} / \mathrm{min}$ ). This effect can improve mucociliary function, airway clearance, and level of comfort to the patient. It can provide controlled and adequate fraction of inspired oxygen $\left(\mathrm{FiO}_{2}\right)$

between $21 \%$ and $100 \%$. Generation of end-expiratory pressure helps in carbon dioxide washout, reduction of anatomical dead space, and recruitment of collapsed alveoli, ultimately improving tissue oxygenation.
\end{abstract}

The use of HFNC in acute hypoxemic respiratory failure, post-extubation period, pre-intubation period, respiratory infection, and obstructive airway disease has been extensively studied, but there are very few studies regarding its use in cardiogenic pulmonary edema. This review provides the current understanding of the physiological effect of HFNC and its application in acute cardiogenic pulmonary edema (ACPE). We conducted a literature search on PubMed using appropriate terms and reviewed relevant articles published within the last 10 years. We found that initial therapy with HFNC in ACPE patients can improve oxygenation and respiratory rate. HFNC can potentially be an alternative to non-invasive positive-pressure ventilation in terms of initial oxygen therapy in patients with ACPE. There is a need for larger prospective studies to evaluate and develop guidelines to consider the use of HFNC in patients with ACPE. We also highlight the fact that if there is no improvement in arterial blood gas parameters after HFNC therapy, initiation of invasive ventilation should not be delayed.

Categories: Cardiology, Internal Medicine, Pulmonology

Keywords: oxygen therapy, acute cardiogenic pulmonary edema, heart failure, acute hypoxic respiratory failure, highflow nasal cannula, non-invasive positive-pressure ventilation

Received 01/13/2021 Review began 01/30/2021 Review ended 02/10/2021 Published 02/16/2021

๑) Copyright 2021 Adhikari et al. This is an open access article distributed under the terms of the Creative Commons Attribution License CC-BY 4.0., which permits unrestricted use, distribution, and reproduction in any medium, provided the original author and source are credited.

\section{Introduction And Background}

Acute cardiogenic pulmonary edema (ACPE) is a major and serious complication of acute heart failure. It has an estimated mortality rate of $10 \%$ in hospitalized patients and a one-year mortality rate as high as $30 \%$ [1]. It is the second most common parenchymal cause of respiratory failure after pneumonia. Overall, $90 \%$ of patients present with dyspnea, while the remaining present with significant respiratory failure in the form of hypoxemia, hypercapnia, and acidosis [2,3]. The initial treatment includes supplemental oxygen, diuretics, vasodilators, non-invasive positive-pressure ventilation (NIPPV) or endotracheal intubation.

Conventional oxygen therapy (COT) with nasal cannula or face mask is the most common method of oxygen delivery. Oxygen supplementation with COT may not always be sufficient and effective. Often there is a need for NIPPV in the form of continuous positive airway pressure (CPAP), bilevel positive airway pressure (BPAP), or even endotracheal intubation [4]. COT cannot provide adequate fraction of inspired oxygen $\left(\mathrm{FiO}_{2}\right)$ if patients' inspiratory flow rate is higher than the oxygen flow from COT. The additional flow is recruited from atmospheric air $\left(\mathrm{FiO}_{2}-21\right)$ which lowers the delivered $\mathrm{FiO}_{2}$. When the oxygen flow is greater than 6 $\mathrm{L} /$ min through COT, even bubble humidifier cannot humidify the oxygen sufficiently, which causes dryness of the respiratory tract [5]. The European Society of Cardiology recommends NIPPV for patients with acute and chronic heart failure whose respiratory rate is more than $20 \mathrm{breaths} / \mathrm{min}$ as an initial therapy to reduce hypercapnia and acidosis [6]. High-flow nasal cannula (HFNC) is being increasingly used currently for acute respiratory failure due to hypoxemia, post-extubation period, pre-intubation period, respiratory infection, and obstructive airway disease. It can deliver a mixture of air and oxygen at a very high flow rate (maximal flow of $60 \mathrm{~L} / \mathrm{min}$ ). The air is heated and humidified and $\mathrm{FiO}_{2}$ can be better regulated [7]. It has been thought that a small positive end-expiratory pressure (PEEP) delivered by the system helps in alveolar recruitment and increased oxygenation of tissues [8]. Some studies have suggested that the use of HFNC reduces nasopharyngeal resistance and pharyngeal dead space $[9,10]$. 
Studies have also shown that HFNC can be a potential therapeutic option in patients with acute respiratory failure. The use of HFNC in respiratory failure specifically due to ACPE has not been studied extensively. Do the physiological effects of HFNC provide better outcome in the management of ACPE? Can it be used as an alternative to NIPPV with better outcome in terms of patients' compliance? We reviewed the mechanism of the physiologic effect of HFNC in respiratory system and searched all available articles published on PubMed within the last 10 years. Research in this field is new and there are no established guidelines for the use of HFNC in ACPE. This review aims to summarize and discuss the current understanding of the physiologic effect of HFNC and its application in ACPE.

\section{Review}

\section{Physiological effects of high-flow nasal cannula}

Humidification of Oxygen and Improvement in Mucociliary Clearance

Inhalation of cold and dry air causes dryness of airways, which can impair mucociliary functions such as secretion clearance and airway defense [11]. Dry airways increase airway resistance and work of breathing. HFNC not only provides high flow but also contains an active heated humidifier which warms and humidifies air before delivering it to the airways [12]. A study by Chikata et al. found that $100 \%$ humidification can be maintained at high flow $(20-50 \mathrm{~L} / \mathrm{min})$ at normal body temperature $\left(37^{\circ} \mathrm{C}\right)$ [13]. The humidified air loosens the thick secretions, improves mucociliary functions, and improves airway clearance [14].

Reduction of Anatomical Dead Space and Increased Carbon Dioxide Washout

Anatomical dead space is defined as "the segments of the respiratory tract responsible for conducting air to the alveoli and respiratory bronchioles which does not take part in gas exchange” [12]. Studies have shown high flow produced by HFNC reduces respiratory rate in patient with moderate-to-severe respiratory distress, which in turn decreases minute ventilation (respiratory rate $\times$ tidal volume), while partial pressure of carbon dioxide remains steady or even decreases. A retrospective study by Jeong et al. demonstrated similar results in patients with hypercapnia who were treated with HFNC in the emergency department [15]. This proves that continuous flow of fresh air at high flow produces a more efficient ventilation by facilitating carbon dioxide clearance from the anatomical dead space $[16,17]$.

Control in Fraction of Inspired Oxygen

The inspiratory flow of a patient varies with each breath. If inspiratory flow is higher than the supplemental oxygen flow, especially with COT, then the remaining air is recruited from the atmosphere. This dilutes the oxygen content and decreases $\mathrm{FiO}_{2}$. HFNC provides high and constant flow and overcomes the issue of gas dilution [18]. $\mathrm{FiO}_{2}$ is more constant at higher flows and can be maintained between 0.21 and 1 [19,20].

Generation of Positive Expiratory Pressure and Alveolar Recruitment

NIPPV is a closed system whereas HFNC is an open system. The high flow through HFNC can provide a small positive pressure in the airways. It has been postulated that opening of the mouth during breathing causes escape of gas, thus reducing the pressure in the airway; however, with mouth closed during breathing and a maximum flow of $60 \mathrm{~L} / \mathrm{min}$, the pharyngeal pressure remains around $3 \mathrm{~cm}$ of water [15,21]. A study by Corley et al. showed a linear relationship between end-expiratory lung volume (EELV) and flow rate. The study showed 0.7\% increase in EELV with each liter increase in flow [22]. The PEEP shifts fluid in the alveolar space to perivascular interstitial space and increases the number of alveoli participating in ventilation, which is also known as alveolar recruitment $[23,24]$.

Reduction in Work of Breathing

Inspiration is an active process whereas expiration is a passive process. Respiratory muscles consume energy during inspiration which is also known as work of breathing [12]. One of the main functions of NIPPV is to assist respiratory muscles by reducing work of breathing. Studies have shown that the use of HFNC can reduce work of breathing in infants with respiratory distress and in adults with chronic obstructive pulmonary disease $[25,26]$. HFNC reduces respiratory rate and improves thoraco-abdominal synchrony during breathing, reducing work of breathing.

Improvement in Patient Comfort

HFNC does not have unwanted effects as observed with nasal or facial mask. Patients can talk and eat while using HFNC. Patients often prefer HFNC to other form of NIPPV (BPAP, CPAP) because they do not have to wear tight-fitting masks which can be uncomfortable. Compared to COT, it is better tolerated because of warmed, humidified gases that do not dry respiratory mucosa [2,27]. Most patients are comfortable using it for a longer period. A summary of the physiological effects of HFNC is presented in Table 1 . 


\section{Cureus}

\section{Physiological effects of HFNC}

Humidification of oxygen and improvement in mucociliary clearance

Reduction of anatomical dead space and increased carbon dioxide washout

Control in fraction of $\mathrm{FiO}_{2}$

Generation of positive expiratory pressure and alveolar recruitment

Reduction in work of breathing

Improvement in patient comfort

TABLE 1: Summary of the physiological effects of HFNC.

$\mathrm{FiO}_{2}$, inspired oxygen; HFNC, high-flow nasal cannula

\section{Adverse effects of high-flow nasal cannula}

In the absence of well-established evidence or criteria, clear contraindication for HFNC is lacking. Some studies have suggested avoiding HFNC in patients for whom NIPPV is contraindicated [14]. However, in fact, HFNC can be an alternative when NIPPV is contraindicated, for example, in patients with claustrophobia and intolerance towards tight interface contact. Although HFNC can cause abdominal distention and barotrauma as other NIPPV, the incidence is very rare [12]. There is no guideline for when to escalate respiratory therapy from HFNC to the invasive form. It depends on the judgement of the physician. Between $30 \%$ and $40 \%$ of patients with acute hypoxic respiratory failure require invasive mechanical ventilation [20]. Delayed intubation is associated with increased mortality in pneumonia [28,29]. Prolonged spontaneous breathing with HFNC may worsen the nature and extent of the initial injury, which is also known as selfinflicted injury. Oxygen supplementation may rapidly normalize oxygen saturation leading to the misjudgment that the patient is improving [30].

\section{Application of high-flow nasal cannula in acute cardiogenic pulmonary edema}

The use of HFNC in acute respiratory failure due to various underlying causes has been extensively studied since its introduction. The investigation is more extensive in acute hypoxemic respiratory failure, postextubation period, pre-intubation period, respiratory infection, and obstructive airway disease [1]. There are very few studies regarding the use of HFNC in respiratory failure due to ACPE. In acute heart failure patients where there is elevated preload and afterload, the use of HFNC can increase cardiac output by reducing both preload and afterload [31,32]. HFNC therapy also reduces intrapulmonary shunting [33]. It provides some degree of PEEP, which increases the intrathoracic pressure. This can cause some degree of inspiratory collapse of inferior vena cava from the patient's baseline and decrease preload. Roca et al. demonstrated this finding in a sequential interval study on 10 patients with New York Heart Association (NYHA) classification III heart failure where the collapse of inferior vena cava was measured by echocardiogram [34]. The use of CPAP has been the first line oxygen therapy for pulmonary edema because of its ability to improve oxygenation and reduce afterload [35]. A similar effect is exhibited by HFNC with less discomfort, which can be an alternative for patients who are not able to tolerate NIPPV. However, more data is needed to show its effectiveness in this population.

One of the randomized controlled trials by Ko et al. compared the use of COT with HFNC in 69 heart failure patients with pulmonary edema presenting to the emergency department (ED). They obtained respiratory rate, oxygen saturation $\left(\mathrm{SpO}_{2}\right)$, lactate levels and arterial blood gas $(\mathrm{ABG})$ parameters at baseline and 30 and 60 minutes. The result showed improvement in all parameters with HFNC therapy compared with conventional therapy [36]. In terms of $A B G$ parameters, there were significant differences in the $\mathrm{PaO}_{2}$ and $\mathrm{SpO}_{2}$. They recommended to consider invasive ventilation if there is no significant improvement in ABG parameters within 30 minutes of HFNC [36]. Another randomized controlled trial by Makdee et al. included 128 ED patients with cardiogenic pulmonary edema who were randomized into COT and HFNC. The results of the study showed that 60-min respiratory rate was significantly lower with HFNC than COT [37]. They concluded that HFNC could deliver effective oxygenation and comfort with minimal complications or lifethreatening adverse events [37].

Sener et al. conducted a prospective observational study in patients with tachypneic, hypoxemic, hypertensive pulmonary edema. Out of 112 patients, 50 underwent standard oxygen therapy and 62 received high-flow oxygen therapy (HFOT). They studied patient's zero, first, and second-hour blood gas result and 
vital signs, requirement of endotracheal intubation, length of hospitalization, and prognosis [4]. The result showed that HFNC can shorten the length of stay both in the ED and intensive care unit. The second-hour lactate levels were significantly lower in the HFOT group suggesting effective tissue and cell oxygenation. HFNC is more effective in patients with hypertensive pulmonary edema than COT in terms of blood gas analysis, heart rate, and respiratory rate in the follow-up period [4]. A cohort study by Chang et al. showed no significant difference in treatment failure within 72 hours among the HFNC and NPPV group [38]. They analyzed 104 patients out of which 58 were in the HFNC group and 46 in the NPPV group. The study concluded that among the patients with heart failure, HFNC was not inferior to NIPPV for preventing extubation failure and reintubation [38]. Studies comparing HFNC with NIPPV/COT are summarized in Table 2.

One of the studies reported that HFNC therapy did not show more benefits compared to COT with respect to endotracheal intubation within 24 hours, intensive care unit admission rate, and 28-day mortality in heart failure patients with acute pulmonary edema [37]. In the study brain natriuretic peptide (BNP) value was statistically higher in the HFNC group than in the COT group. The BNP value increases when left ventricular systolic function decreases [27]. The higher value of BNP is proportional to the severity of heart failure according to the NYHA classification. As the BNP value was significantly higher in the HFNC group than in the COT group, HFNC may have greater degree of severity of heart failure.

\begin{tabular}{|c|c|c|c|c|}
\hline Study & Study population & $\begin{array}{l}\text { Intervention/Experimental } \\
\text { group }\end{array}$ & $\begin{array}{l}\text { Control } \\
\text { group }\end{array}$ & Outcome \\
\hline $\begin{array}{l}\text { Ko et al. }[36] \\
\text { (Randomized } \\
\text { controlled trial) }\end{array}$ & $\begin{array}{l}\text { Patient suspected of } \\
\text { pulmonary edema due to } \\
\text { heart failure }\end{array}$ & HFNC $(n=36)$ & $\begin{array}{l}\operatorname{col}(\mathrm{n} \\
=33)\end{array}$ & $\begin{array}{l}\text { Significant difference in respiratory rate, } \mathrm{SpO}_{2} \text { at } 30 \text { and } \\
60 \text { minutes (improved in } \mathrm{HFNC} \text { group) Significant } \\
\text { difference in } \mathrm{ABG} \text { parameters }\left(\mathrm{PaO}_{2} \text { and } \mathrm{SpO}_{2}\right) \text { at } 30 \text { and } \\
60 \text { minutes (improved in } \mathrm{HFNC} \text { group) }\end{array}$ \\
\hline $\begin{array}{l}\text { Makdee et al. } \\
\text { [37] (Randomized } \\
\text { controlled trial) }\end{array}$ & $\begin{array}{l}\text { ED patients with } \\
\text { cardiogenic pulmonary } \\
\text { edema }\end{array}$ & HFNC $(n=63)$ & $\begin{array}{l}\text { COT }(\mathrm{n} \\
=65)\end{array}$ & $\begin{array}{l}\text { 60-minute respiratory rate significantly lower in HFNC } \\
\text { group Lower respiratory rate at } 15 \text { and } 30 \text { minutes in } \\
\text { HFNC group }\end{array}$ \\
\hline $\begin{array}{l}\text { Sener et al. }[4] \\
\text { (Prospective } \\
\text { observational } \\
\text { study) }\end{array}$ & $\begin{array}{l}\text { Patients with } \\
\text { hypertensive pulmonary } \\
\text { edema }\end{array}$ & HFNC $(n=62)$ & $=50)$ & $\begin{array}{l}\text { HFNC shortens the length of stay in both emergency and } \\
\text { intensive care unit HFNC shows better results in terms of } \\
\text { heart rate, respiratory rate, and ABG parameters }\end{array}$ \\
\hline $\begin{array}{l}\text { Chang et al. [38] } \\
\text { (Cohort study) }\end{array}$ & $\begin{array}{l}\text { Post-extubated patients } \\
\text { with heart failure with } \\
\text { ejection fraction }<50 \%\end{array}$ & HFNC $(n=58)$ & $\begin{array}{l}\text { NIPPV } \\
(n=46)\end{array}$ & $\begin{array}{l}\text { No significant difference in treatment failure between two } \\
\text { groups in } 72 \text { hours }\end{array}$ \\
\hline \multicolumn{5}{|c|}{$\begin{array}{l}\text { TABLE 2: Studies on use of HFNC in ACPE showing study population, intervention/experimental } \\
\text { group, control group, and outcome. }\end{array}$} \\
\hline \multicolumn{5}{|c|}{$\begin{array}{l}\mathrm{HFNC} \text {, high-flow nasal cannula, COT, conventional oxygen therapy; } \mathrm{NIPPV} \text {, non-invasive positive-pressure ventilation; ABG, arterial blood gas; } \\
\mathrm{SpO}_{2} \text {, oxygen saturation; } \mathrm{PaO}_{2} \text {, partial pressure of oxygen; n, number of participants; ACPE, acute cardiogenic pulmonary edema }\end{array}$} \\
\hline
\end{tabular}

\section{Conclusions}

Whether the use of HFNC provides an improved outcome in ACPE is a subject of interest. The use of HFNC in acute respiratory failure secondary to acute hypoxemic respiratory failure, post-extubation period, preintubation period, respiratory infection, and obstructive airway disease has been studied extensively. However, the data on the use of HFNC in ACPE is scarce. HFNC therapy provides heated and humidified oxygen, which is better tolerated by most patients. Generation of positive expiratory pressure, carbon dioxide washout, reduction in anatomical dead space, alveolar recruitment, and ability to deliver desired $\mathrm{FiO}_{2}$ helps in better oxygenation in patients with ACPE. Reduction of preload and afterload in the heart makes it a potential initial therapy in ACPE. It can potentially replace COT and act as an alternative to NIPPV as an initial effective oxygen therapy in patients with ACPE.

There is a need for larger prospective comprehensive studies to evaluate and develop guidelines to determine when invasive ventilation is appropriate in patients with cardiogenic pulmonary edema on HFNC therapy. If there is no improvement in ABG parameters after HFNC therapy, the physician should consider invasive ventilation.

\section{Additional Information}




\section{Disclosures}

Conflicts of interest: In compliance with the ICMJE uniform disclosure form, all authors declare the following: Payment/services info: All authors have declared that no financial support was received from any organization for the submitted work. Financial relationships: All authors have declared that they have no financial relationships at present or within the previous three years with any organizations that might have an interest in the submitted work. Other relationships: All authors have declared that there are no other relationships or activities that could appear to have influenced the submitted work.

\section{References}

1. Rudiger A, Harjola VP, Müller A, Mattila E, Säila P, Nieminen M, Follath F: Acute heart failure: clinical presentation, one-year mortality and prognostic factors. Eur J Heart Fail. 2005, 7:662-670. 10.1016/j.ejheart.2005.01.014

2. Lodeserto FJ, Lettich TM, Rezaie SR: High-flow nasal cannula: mechanisms of action and adult and pediatric indications. Cureus. 2018, 26:3639. 10.7759/cureus.3639

3. Parke RL, McGuinness SP: Pressures delivered by nasal high flow oxygen during all phases of the respiratory cycle. Respir Care. 2013, 58:1621-1624. 10.4187/respcare.02358

4. Şener K, Çalış M, Köseoğlu Z, Sarı S, Polat M, Üzücek DM, Yolcu S: Comparison of high-flow oxygen treatment and standard oxygen treatment in patients with hypertensive pulmonary edema. Anatol J Cardiol. 2020, 24:260-266. 10.14744/AnatolJCardiol.2020.50680

5. Lee CC, Mankodi D, Shaharyar S, et al.: High flow nasal cannula versus conventional oxygen therapy and non-invasive ventilation in adults with acute hypoxemic respiratory failure: a systematic review. Respir Med. 2016, 121:100-108. 10.1016/j.rmed.2016.11.004

6. McMurray JJ, Adamopoulos S, Anker SD, et al.: ESC guidelines for the diagnosis and treatment of acute and chronic heart failure 2012: the Task Force for the Diagnosis and Treatment of Acute and Chronic Heart Failure 2012 of the European Society of Cardiology. Developed in collaboration with the heart failure association (HFA) of the ESC. Eur Heart J. 2012, 33:1787-1847. 10.1093/eurjhf/hfs105

7. Roca O, Riera J, Torres F, Masclans JR: High-flow oxygen therapy in acute respiratory failure . Respir Care. 2010, 55:408-413.

8. Zhu Y, Yin H, Zhang R, Wei J: High-flow nasal cannula oxygen therapy versus conventional oxygen therapy in patients with acute respiratory failure: a systematic review and meta-analysis of randomized controlled trials. BMC Pulm Med. 2017, 13:17. 10.1186/s12890-017-0525-0

9. Booth S, Kelly MJ, Cox NP, Adams L, Guz A: Does oxygen help dyspnea inpatients with cancer? . Am J Respir Crit Care Med. 1996, 153:1515-1518. 10.1164/ajrccm.153.5.8630595

10. Bruera E, Sweeney C, Willey J, Palmer JL, Strasser F, Morice RC, Pisters K: A randomized controlled trial of supplemental oxygen versus air in cancer patients with dyspnea. Palliat Med. 2003, 17:659-663. 10.1191/0269216303pm826oa

11. Frat JP, Ricard JD, Quenot JP, et al.: FLORALI-2 study group; REVA network. Non-invasive ventilation versus high-flow nasal cannula oxygen therapy with apnoeic oxygenation for preoxygenation before intubation of patients with acute hypoxaemic respiratory failure: a randomised, multicentre, open-label trial. Lancet Respir Med. 2019, 7:303-312. 10.1016/S2213-2600(19)30048-7

12. Spicuzza L, Schisano M: High-flow nasal cannula oxygen therapy as an emerging option for respiratory failure: the present and the future. Ther Adv Chronic Dis. 2020, 13:2040622320920106. $10.1177 / 2040622320920106$

13. Chikata $\mathrm{Y}$, Izawa $\mathrm{M}$, Okuda N, et al.: Humidification performance of two high-flow nasal cannula devices: a bench study. Respir Care. 2014, 59:1186-1190. 10.4187/respcare.02932

14. Nishimura M. : High-flow nasal cannula oxygen therapy in adults: physiological benefits, indication, clinical benefits, and adverse effects. Respir Care. 2016, 61:529-541. 10.4187/respcare.04577

15. Jeong JH, Kim DH, Kim SC, et al.: Changes in arterial blood gases after use of high-flow nasal cannula therapy in the ED. Am J Emerg Med. 2015, 33:1344-1349. 10.1016/j.ajem.2015.07.060

16. Nishimura M: High-flow nasal cannula oxygen therapy in adults . J Intensive Care. 2015, 3:15. 10.1186/s40560-015-0084-5

17. Biselli P, Fricke K, Grote L, et al.: Reductions in dead space ventilation with nasal high flow depend on physiological dead space volume: metabolic hood measurements during sleep in patients with COPD and controls. Eur Respir J. 2018, 30:1702251. 10.1183/13993003.02251-2017

18. Ritchie JE, Williams AB, Gerard C, Hockey H: Evaluation of a humidified nasal high-flow oxygen system, using oxygraphy, capnography and measurement of upper airway pressures. Anaesth Intensive Care. 2011, 39:1103-1110. 10.1177/0310057X1103900620

19. Sun YH, Dai B, Peng Y, Tan W, Zhao HW: Factors affecting FiO2 and PEEP during high-flow nasal cannula oxygen therapy: a bench study. Clin Respir J. 2019, 13:758-764. 10.1111/crj.13087

20. Ricard JD, Roca O, Lemiale V, et al.: Use of nasal high flow oxygen during acute respiratory failure . Intensive Care Med. 2020, 46:2238-2247. 10.1007/s00134-020-06228-7

21. Parke R, McGuinness S, Eccleston M: Nasal high-flow therapy delivers low level positive airway pressure . $\mathrm{Br}$ J Anaesth. 2009, 103:886-890. 10.1093/bja/aep280

22. Corley A, Caruana LR, Barnett AG, Tronstad O, Fraser JF: Oxygen delivery through high-flow nasal cannulae increase end-expiratory lung volume and reduce respiratory rate in post cardiac surgical patients. $\mathrm{Br} \mathrm{J}$ Anaesth. 2011, 107:998-1004. 10.1093/bja/aer265

23. Dysart K, Miller TL, Wolfson MR, Shaffer TH: Research in high flow therapy: mechanisms of action . Respir Med. 2009, 103:1400-1405. 10.1016/j.rmed.2009.04.007

24. Parke RL, Bloch A and McGuinness SP: Effect of very-high-flow nasal therapy on airway pressure and endexpiratory lung impedance in healthy volunteers. Respir Care. 2015, 60:1397-1403. 10.4187/respcare.04028

25. Lavizzari A, Veneroni C, Colnaghi M, et al.: Respiratory mechanics during NCPAP and HHHFNC at equal distending pressures. Arch Dis Child Fetal Neonatal. 2014, 99:315-320. 10.1136/archdischild-2013-305855 
26. Pisani L, Astuto M, Prediletto I, Longhini F: High flow through nasal cannula in exacerbated COPD patients: a systematic review. Pulmonology. 2019, 25:348-354. 10.1016/j.pulmoe.2019.08.001

27. Frat JP, Coudroy R, Marjanovic N, Thille AW: High-flow nasal oxygen therapy and noninvasive ventilation in the management of acute hypoxemic respiratory failure. Ann Transl Med. 2017, 5:297. 10.21037/atm.2017.06.52

28. Rello J, Pérez M, Roca O, et al.: High-flow nasal therapy in adults with severe acute respiratory infection: a cohort study in patients with 2009 influenza A/H1N1v. J Crit Care. 2012, 27:434-439. 10.1016/j.jcrc.2012.04.006

29. Bellani G, Laffey JG, Pham T, et al.: Noninvasive ventilation of patients with acute respiratory distress syndrome. insights from the LUNG SAFE study. Am J Respir Crit Care Med. 2017, 195:67-77. 10.1164/rccm.201606-13060C

30. Nedel WL, Deutschendorf C, Moraes Rodrigues Filho E: High-flow nasal cannula in critically ill subjects with or at risk for respiratory failure: a systematic review and meta analysis. Respir Care. 2017, 62:123-132. 10.4187/respcare.04831

31. Pinsky MR, Summer WR, Wise RA, Permutt S, Bromberger-Barnea B: Augmentation of cardiac function by elevation of intrathoracic pressure. J Appl Physiol Respir Environ Exerc Physiol. 1983, 54:950-955. 10.1152/jappl.1983.54.4.950

32. Bradley TD, Holloway RM, McLaughlin PR, Ross BL, Walters J, Liu PP: Cardiac output response to continuous positive airway pressure in congestive heart failure. Am Rev Respir Dis. 1992, 145:377-382. 10.1164/ajrccm/145.2_Pt_1.377

33. Lin M, Yang YF, Chiang HT, Chang MS, Chiang BN, Cheitlin MD: Reappraisal of continuous positive airway pressure therapy in acute cardiogenic pulmonary edema. Short-term results and long-term follow-up. Chest. 1995, 107:1379-1386. 10.1378/chest.107.5.1379

34. Roca O, Pérez-Terán P, Masclans JR, Pérez L, Galve E, Evangelista A, Rello J: Patients with New York Heart Association class III heart failure may benefit with high flow nasal cannula supportive therapy: high flow nasal cannula in heart failure. J Crit Care. 2013, 28:741-746. 10.1016/j.jcrc.2013.02.007

35. Ou X, Hua Y, Liu J, Gong C, Zhao W: Effect of high-flow nasal cannula oxygen therapy in adults with acute hypoxemic respiratory failure: a meta-analysis of randomized controlled trials. CMAJ. 2017, 21:260-267. 10.1503/cmaj.160570

36. Ko DR, Beom J, Lee HS, You JS, Chung HS, Chung SP: Benefits of high-flow nasal cannula therapy for acute pulmonary edema in patients with heart failure in the emergency department: a prospective multi-center randomized controlled trial. J Clin Med. 2020, 21:1937. 10.3390/jcm9061937

37. Makdee O, Monsomboon A, Surabenjawong U, et al.: High-flow nasal cannula versus conventional oxygen therapy in emergency department patients with cardiogenic pulmonary edema: a randomized controlled trial. Ann Emerg Med. 2017, 70:465-462. 10.1016/j.annemergmed.2017.03.028

38. Chang CJ, Chiang LL, Chen KY, Feng PH, Su CL, Hsu HS: High-flow nasal cannula versus noninvasive positive pressure ventilation in patients with heart failure after extubation: an observational cohort study. Can Respir J. 2020, 3:6736475. 10.1155/2020/6736475 